copy I have received, and also that the "May, 1875 " has a line drawn through it. While on the subject let me add that the Zoological Society itself, in its "Transactions," sets a bad example in this respect. Each paper bears a date at the foot of its first page, but the date is likely to be misleading in years to come, for it is that of the printing off the sheet-an essentially private matter, with which the public has nothing to do-and not that of the publication.

Another F. Z. S.

\section{Meteor Observations}

A BRIEF summary of the August (Perseid) meteor observa. tions at York may be of interest.

Watch was kept on the Ioth, IIth, I2th, and I4th. The night of the I Ith was very hazy, the rights before the roth cloudy. There was also much moonlight, except on the 14th. Yet, after making all due allowances, Prof. Herschel thinks that this year's shower indicates a minimum; the last decided minimum being in 1862 .

The hourly number on the four nights mentioned were, for one observer, $22,8,12,15$, respectively. Perseid radiant and sub-radiants gave $18,6,9,7$. Thus, as the shower progressed, there was a regular decrease in the number of Perseids. The apparent exception of the Ioth was due to the haze. Prof. Herschel gives I5-20 as the hourly number in Kent. On the I4th half the Perseids came from Mr. Greg's sub-radiant at $\gamma$ Cassiopeix.

In the south large meteors appear to have been scarce. Here eight, brighter than ist mag. stars, were seen. One, a bolide, low down in the N.W. was very fine. A meteor in the south-west, brighter than Jupiter, was observed by Mr. Waller at Birmingham as a very brilliant object.

The total number observed at York was 105, and 90 of these were mapped. Of the latter 66 were Perseids, 43 with trains. On the roth five other radiants produced eight meteors out of 53; viz., Cygnus, three; Pegasus, two; Polaris, one; Draco (Hercules), one ; and Ursa Major, one. Fifteen meteors on this night were as bright, or brighter, than a I mag. star. Only two of $4_{\text {th }}$ mast. brightness were seen, in consequence of the moonlight.

Of meteors stationary, or nearly so, three were mapped:-A Perseid on the $\mathrm{r} 2 \mathrm{th}$ at $\mathcal{R} 32 \frac{1}{2}$ and $\delta+58 \frac{3}{2}$, its train lasting $2 \frac{1}{2}$ secs. ; on the r 4 th a Cygneid at $\mathbb{R} 306^{\circ} \delta+35^{\circ}$, and an unknown radiant, probably near 5 Vulpecula, gave the third at $\mathbb{R}$ $295^{\circ} \delta+28$.

Three meteors unmistakably confirm Mr. Greg's sub-Perseid radiant by $\gamma$ Cassiopeiæ, whilst several others probably radiate from the same. The radiant, Greg 83 , by $\eta$ Draconis, gave two meteors on the 12 th and one on the I4th. It is put down, however, as lasting only from July $12-3 \mathrm{I}$.

Six Perseids on the roth, and four on other nights, seem pretty clearly to indicate a sub-radiant at $\mathbb{R} 50^{\circ}, \delta+40^{\circ}$, near a Persei. The rest, as Prof. Herschel also noticed, shot very constantly from the chief radiant, between $\eta$ and $\chi$ Persei. Here, however, $\eta$ Persei seemed the most central point.

York, Aug. 15

\section{J. Edmund Clark}

\section{THE FRENCH ASSOCIATION}

$\mathrm{IN}$ addition to the notes already given with regard to the forthcoming meeting of the French Association at Clermont, the following particulars relating to the Puyde-Dome (furnished by our correspondent there) will doubtless be found interesting :-

\section{Clernont, August I3}

The Puy-de-Dôme is connected with most important scientific events, which render it notable amongst more lofty mountains.

Pascal, in 1644 , then quite a young man, was apprised by Pere Mersenne, the celebrated friend of Descartes, that Torricelli had invented his tube. The then admitted explanation was that nature abhorred a vacuum.

He entered into a correspondence on the subject with Father Noel, a Jesuit professor of natural philosophy in the College of Clermont. Father Noel contended against the very existence of the vacuum, and asserted that the so-called vacuum was filled by luminous matter entering through the glass. Pascal answered by arguments worthy of his genius, and to be recommended for consideration in the discussion about radiometers. He said,
"As the nature of light is known to neither you nor $m e$, and as it is very likely it will always be so, $I$ see it will be long before your reasoning acquires the force which is necessary to its becoming the source of any conviction." After having uttered this opinion he reflected more fully upon the subject, and was led to believe that the surplus height of mercury in the tube was equivalent to the weight of the air which could not reach the molecules, being intercepted by the resistance of the glass. This led him to inquire if air-pres. sure was not lessened by taking the Torricellian tube to the top of a mountain, The experiment was made in Paris first on the top of St. Jacques la Boucherie Tower and Notre Dame. As the difference was found to be only a few lines, Pascal sent his brother-in-law, Perrier, who was a counsellor in the Cour-des-Aules at Clermont, to the top of Puy-de-Dôme with a Torricellian tube. Clermont was supposed to be at an altitude greater than Paris by 400 toises; Font-de-l'Arbre is a village in the vicinity of the mountains where carriages are obliged to stop, at 250 toises from Clermont, and 250 toises from the top of the mountain. All these measurements are incorrect ; a toise being I' 94 metres, we find the following differences:- Paris, 60 metres, Clermont, 407 ; difference, 347 metres, instead of 776 , as assumed by Pascal; Puy-de-Dôme, I,465. Difference between Puy and Clermont $=1,058$ metres ; according to Pascal only 952 metres.

The loss of mercury from Couvent des Minimes to the top of Puy was found to be $37 \frac{1}{2}$ lines ; at Font-de-l'Arbre a diminution of $14 \frac{1}{2}$ lines from Minimes. A line is equal to $2 \frac{1}{4} \mathrm{~mm}$

Perrier discovered no difference, owing to the wind or state of the atmosphere. Such was not the opinion of Pascal, who discovered that the mercury varies according to the atmospheric conditions of the air. But Perrier was only an amateur experimentalist, and his special ideas had little weight with his clever brother-in-law.

In order to ascertain the fact, continuous abservations were made at Clermont, by Perrier, during the years I649, I650, and I65I. They were simuitaneously made at Paris and at Stockholm, where Descartes was then living at the court of the famous Queen of Sweden. They were continued by Descartes up to the time of his demise.

It is strange that the Pascal experiments were made the very year when Torricelli died, and the results published only in I664, two years after Pascal's death.

\section{THE SCIENCE DEGREES OF THE UTN- VERSITY OF LONDON}

WE have received from the Registrar of the University of London a copy of the Report of a Committee, and the new regulations which have been introduced in harmony with that Report, in the examinations for the science degrees. From a perusal of the Report, which we subjoin, all will feel how much is gained by the prompt action of the Senate of the University in so speedily modifying the plan of their examinations in accordance with the experience which they have obtained during the last seventeen years. It is not however, only experience in the examination of science students which has led to the necessity for change, but the stimulus which has been given to the teaching of physics and biology, by the founding of science degrees and otherwise, has so altered the method of teaching these subjects that what was expected to be known formerly is quite different from that taught by the most able exponents of the subjects at the present time.

No change has been made in the Examination for the Doctor of Science degree, which we regret, because in the Report of the Duke of Devonshire's Committee on Scientific Education great stress was laid on the importance of obtaining an original thesis from each candidate.

The Report of the Committee runs as follows:- 